\title{
Internal hernia caused by a free intraperitoneal staple after laparoscopic appendectomy
}

\author{
Lisa M. Angotti, Christopher Decker, Brittany Pahwa, Carl Rosati, Todd Beyer* \\ Department of General Surgery, Albany Medical Center, Albany, NY, United States
}

Received: April 28, 2018

Accepted: May 6, 2018

Online Published: May 18, 2018

DOI: $10.5430 /$ css.v4n1p14

URL: https://doi.org/10.5430/css.v4n1p14

\begin{abstract}
Background: Laparoscopic appendectomy is the gold standard for treatment of appendicitis. Stapled closure of the appendiceal stump is commonly performed and has several advantages. Few prior cases have demonstrated complications from free staples left within the abdomen after the stapler has been fired.

Case report: A 29-year-old female underwent laparoscopic appendectomy for acute uncomplicated appendicitis during which the appendix and mesoappendix were divided using laparoscopic gastrointestinal anastomosis (GIA) staplers. Her initial recovery was uncomplicated. She returned on postoperative day 17 with sharp mid-abdominal pain, obstipation, and emesis. Her abdomen was distended, and she had a mild leukocytosis. Computed tomography (CT) demonstrated twisted loops of dilated small bowel in the right lower quadrant with two transition points, suggestive of internal hernia with closed loop bowel obstruction. Diagnostic laparoscopy was performed through the three prior appendectomy incisions. An adhesion between the Veil of Treves and the mesentery of the ileum caused by a solitary free closed staple, remote from the staple lines, had caused an internal hernia. The hernia was reduced, and the small bowel was noted to have early ischemic discoloration. The adhesion was lysed by removing the staple from both structures. The compromised loops of bowel began to show peristaltic movement and color returned to normal, and the procedure was concluded without resection. She was discharged home the following day.

Conclusions: Gastrointestinal staplers are commonly used due to ease of use and low complication rate. It is not uncommon to leave free staples in the abdomen as retrieval can be difficult and time consuming. Our case is only the second in the literature reporting an internal hernia with closed loop bowel obstruction as a complication of retained staples. Choosing the most appropriate size staple load to reduce the number of extra staples, removing free staples, or the use of an endoloop can prevent potentially devastating complications.
\end{abstract}

Key Words: Internal hernia, Bowel obstruction, Laparoscopy, Gastrointestinal staplers, Appendectomy

\section{INTRODUCTION}

Approximately 520,000 appendectomies are performed annually in the United States, of which $81 \%$ are completed laparoscopically. ${ }^{[1]}$ The laparoscopic appendectomy has been considered the gold standard since the mid-1990's, boasting less pain, lower risk of infection, and a shorter hospital stay. [2]
Regarding closure of the appendiceal stump, various techniques have been described and used, the most common being endoscopic loop or staple ligation. With similar outcomes, the staple technique had been documented to have lower risk of infection and shorter operating room time. ${ }^{[3-5]}$

While significant literature has demonstrated postoperative complications from retained surgical clips, after a laparo-

*Correspondence: Todd Beyer; Email: beyert@amc.edu; Address: Department of General Surgery, Albany Medical Center, 43 New Scotland Ave. Albany, NY 12208, United States. 
scopic cholecystectomy for example, few cases have been reported demonstrating complications from free staples left within the abdominal cavity after the laparoscopic stapler has been fired. ${ }^{[6-11]}$

\section{CASe Presentation}

A previously healthy 29-year-old female originally presented to the emergency department with a one day history of right lower quadrant abdominal pain, and on abdominal ultrasound had findings consistent with acute appendicitis. She was taken to the operating room for a laparoscopic appendectomy, at which time both the appendix and mesoappendix were divided using laparoscopic gastrointestinal anastomosis (GIA) staplers. Her initial postoperative recovery was uncomplicated, and she was discharged home the same day, tolerating a regular diet. The pathology was consistent with acute appendicitis.

The patient returned to the emergency department on postoperative day 17 with one day of sharp mid-abdominal pain, obstipation, and one episode of emesis. She was afebrile without hypotension or tachycardia. On physical exam, her abdomen was distended and mildly tender, and she had a leukocytosis with a white blood cell count of 13,200 cells $/ \mathrm{mm}^{3}$ [normal 4,100-9,300 cells $/ \mathrm{mm}^{3}$ ]. Computed tomography (CT) demonstrated twisted loops of dilated small bowel in the right lower quadrant with two transition points, and decompressed small bowel proximal and distal to this region, suggestive of internal hernia with closed loop bowel obstruction (see Figure 1). A nasogastric tube was placed with resolution of the patient's abdominal pain. However, given the concerning CT findings, the patient was taken back to the operating room for a diagnostic laparoscopy.

Ports were placed through the three prior appendectomy incisions, and upon exploration dilated loops of small bowel were immediately noted in the right lower quadrant. The prior appendectomy staple lines were identified and noted to be healing well. The bowel was run proximally from the ileocecal valve. A solitary free closed staple, remote from the staple lines, had caught both the Veil of Treves and the mesentery of a more proximal loop of ileum in the two curled ends, creating an enclosed space between the two structures. Several loops of ileum had become incarcerated within this space, resulting in an internal hernia with a closed loop small bowel obstruction (see Figure 2). The small bowel was reduced and was noted to have early ischemic discoloration (see Figure 3). The adhesion was lysed by removing the staple from both structures to prevent recurrence. The remainder of the small bowel was run without additional pathology noted. Through the remainder of the procedure, the compromised loops of bowel began to show peristaltic

Published by Sciedu Press movement and color returned to normal. The procedure was concluded without resection, and the port sites were closed.

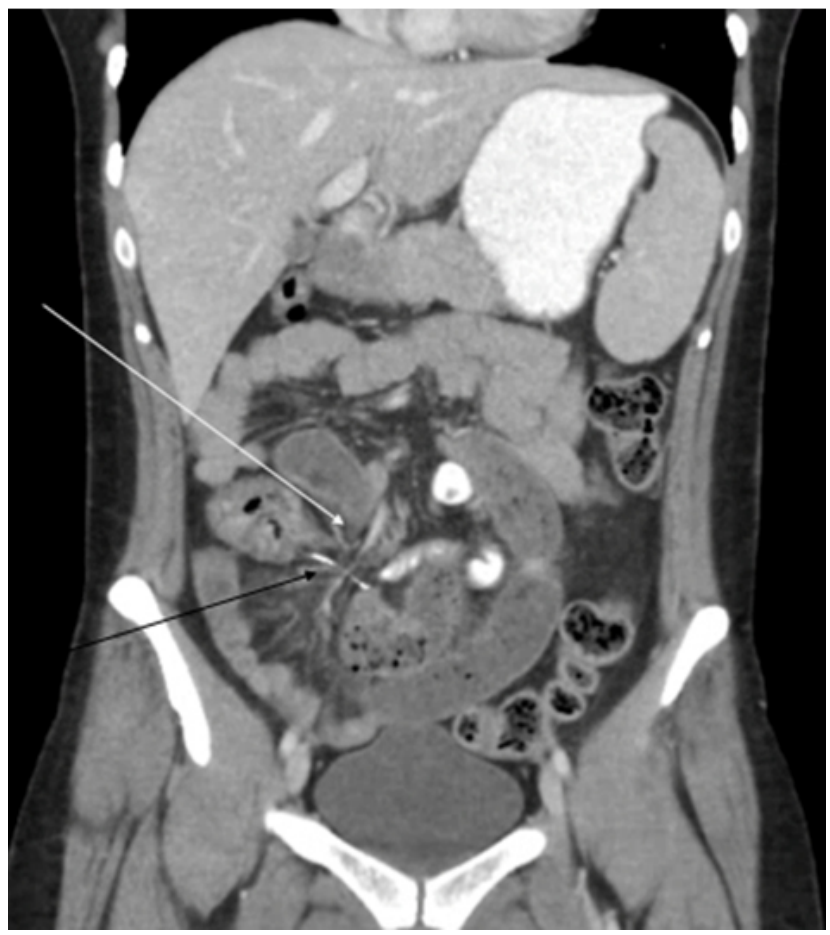

Figure 1. CT demonstrating concern for bowel obstruction, coronal view

Black arrow indicates apparent metallic foreign body. White arrow indicates transition point with dilated small bowel superiorly

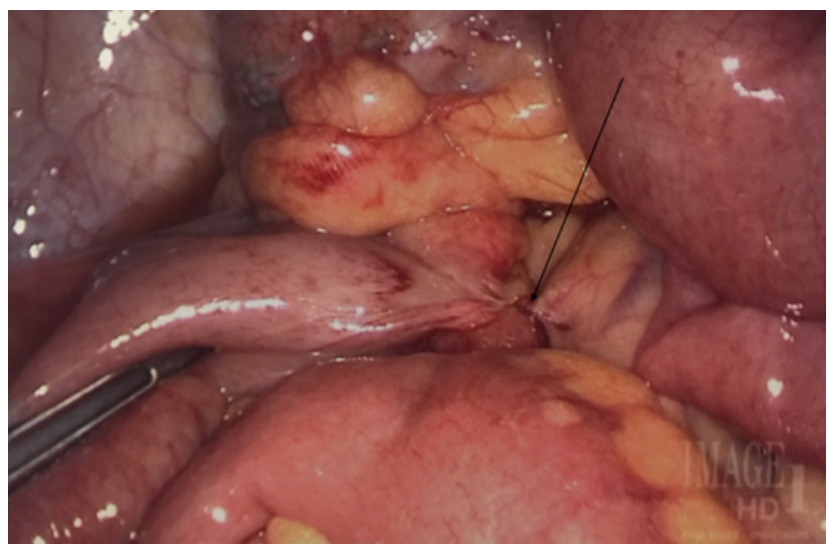

Figure 2. Adhesion between the Veil of Treves and the mesentery of the ileum caused by a free closed staple, resulting in an internal hernia

Arrow indicates location of staple and resulting adhesion

The patient recovered on a surgical floor. Her prior symptoms resolved, and she was discharged home on postoperative day one, tolerating a regular diet. She was seen in the General Surgery clinic on postoperative day eight and was feeling well with an uncomplicated recovery. 


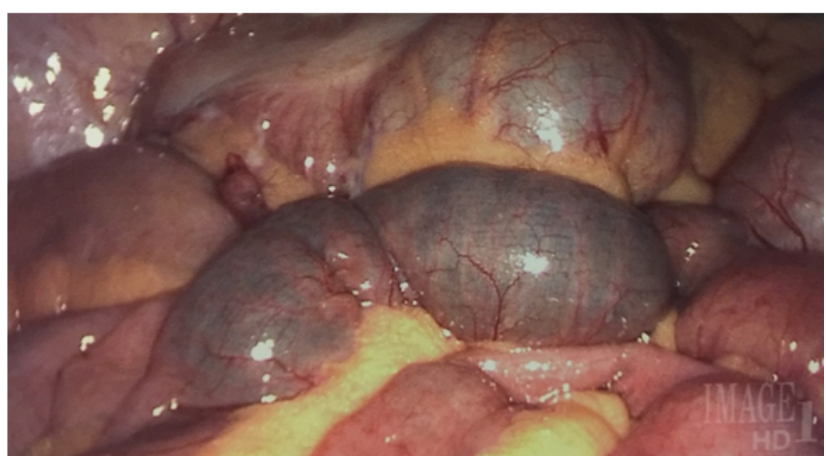

Figure 3. Discolored and dilated small bowel immediately after reduction of internal hernia

\section{Discussion}

Laparoscopic appendectomy is considered the gold standard in management of acute appendicitis. Gastrointestinal staplers are commonly used during these and other intraabdominal procedures secondary to ease of use and low complication rate. ${ }^{[3]}$ It is not uncommon to leave free staples in the abdomen, especially during laparoscopic procedures where retrieval can often be more difficult and time consuming.

Prior studies have shown multiple complications of retained foreign bodies. Clips leading to biliary stone formation are among the most frequently reported. ${ }^{[6-9]}$ Staples have also been reported in several cases to cause complications, including two prior cases of small bowel obstruction caused by adhesions to the appendiceal staple line. ${ }^{[10,11]}$ Free staples have also been reported to cause small bowel obstructions, with two cases noting staples has a nidus for adhesion formation. ${ }^{[12,13]}$ However, our case is only the second case in the literature reporting a free staple leading to an internal hernia with closed loop bowel obstruction, demonstrating an example of a potentially dangerous complication. ${ }^{[14]}$

Our patient required a second operation and had early bowel ischemia that could have resulted in the need for bowel resection if there had been a delay in presentation or treatment. Therefore, it is highly recommended to choose the most appropriate size staple load to reduce the number of extra staples after deployment and to remove all free staples when possible. This can be extrapolated to other foreign bodies, such as surgical clips, as these have also been documented to cause postoperative complications. ${ }^{[6-9]}$ Although this may increase initial operative times, it will undoubtedly reduce potential devastating effects during the postoperative course. In addition, the use of an endoloop to close the appendiceal stump has been shown to be safe and avoids the need to remove free staples. ${ }^{[4,5]}$ Finally, hook diathermy or other energy devices can be used to divide the mesoappendix, providing hemostasis without leaving a foreign body.

\section{CONFliCtS OF INTEREST Disclosure}

The authors declare they have no conflicts of interest.

\section{REFERENCES}

[1] Truven Health Analytics (Thomson/Solucient). USA Procedure Volumes. 2014.

[2] Ruffolo C, Fiorot A, Pagura G, et al. Acute appendicitis: What is the gold standard of treatment? World J Gastroenterol. 2013; 19(47): 8799-8807. PMid: 24379603. https://doi.org/10.3748/wjg. v19.i47.8799

[3] Kazemier G, Hof KHI, Saad S, et al. Securing the appendiceal stump in laparoscopic appendectomy: evidence for routine stapling? Surg Endosc. 2006 Sep; 20(9):1473-6. PMid: 16823654 https://doi.org/10.1007/s00464-005-0525-7

[4] Swank HA, van Rossem CC, van Geloven AA, et al. Endostapler or endoloops for securing the appendiceal stump in laparoscopic appendectomy. Surgical Endoscopy. 2014; 28: 576-583. PMid: 24048816. https://doi.org/10.1007/s00464-013-3207-x

[5] Sahm M, Kube R, Schmidt S, et al. Current analysis of endoloops in appendiceal stump closure. Surg Endosc. 2011 Jan; 25(1): 124 9. PMid: 20552371. https://doi.org/10.1007/s00464-010 $-1144-5$

[6] Brutvan FM, Kampshroer BH, Parker HW. Vessel clip as a nidus for formation of a common duct stone. Gastrointest Endosc. 1982; 28 222-3. https://doi.org/10.1016/S0016-5107 (82) 73080-9

[7] Margolis JL. Recurrent choledocholithiasis due to hemostatic clip. Arch Surg. 1986; 121: 1213. PMid: 3767657. https://doi.org/ 10.1001/archsurg.1986.01400100125026
[8] Ghazanfari K, Gollapudi PR, Konicek FJ, et al. Surgical clip as a nidus for common bile duct stone formation and successful endoscopic therapy. Gastrointest Endosc. 1992; 38: 611-3. https: //doi.org/10.1016/S0016-5107(92)70532-X

[9] Herline AJ, Fisk JM, Debelak JP, et al. Surgical clips: a cause of late recurrent gallstones. Am Surg. 1998; 64: 845-8. PMid: 9731811.

[10] Rajan M, Dip F, Szomstein S, et al. Staple line as a cause of unusual early internal hernia after appendectomy. Int J Surg. 2014; 12 Suppl 1: S159-61. PMid: 24859400. https://doi.org/10.1016/j.ij su. 2014.05.021

[11] Petersen LF, Nally MC, Agos A, et al. Internal hernia and small bowel obstruction caused by a linear cutter staple at appendiceal stump following laparoscopic appendectomy. J Surg Case Rep. 2014; 1. https://doi.org/10.1093/jscr/rjt114

[12] Craig DH, Lagergren E, Sieren LM. Mechanical Small Bowel Obstruction Caused by a Retained Free Intraperitoneal Staple Following Laparoscopic Appendectomy. Am Surg. 2016; 82(12): e369-370. PMid: 28234173.

[13] Chepla KJ, Wilhelm SM. Delayed Mechanical Small Bowel Obstruction Caused by Retained, Free, Intraperitoneal Staple After Laparoscopic Appendectomy. Surg Laparosc Endosc Percutan Tech. 2011; 21(1): e19-20. PMid: 21304366. https://doi.org/10.1097/SL E. $0 \mathrm{~b} 013 \mathrm{e} 3182051 \mathrm{ffe}$

[14] Nottingham JM. Mechanical small bowel obstruction from a loose linear cutter staple after laparoscopic appendectomy. Surg Laparosc Endosc Percutan Tech. 2002 Aug; 12(4): 289-90. PMid: 12193829. https://doi.org/10.1097/00129689-200208000-00019 